\title{
Qualitative differences in Beginner Teachers' knowledge of students' understandings: evidence from Learning Study and implications for teacher education
}

\author{
Guy Durden \\ Department of Curriculum, Pedagogy and Assessment, UCL - Institute of Education, \\ London, UK
}

\begin{abstract}
This study contributes to teacher educators' pedagogical content knowledge by drawing on phenomenography-variation theory to: i) research and describe qualitative differences in Beginner Teachers' conceptions of students' understandings of subject content and, ii) provide evidence of the effectiveness of an instructional strategy that might be adopted by teacher educators based upon those conceptions (known as 'Learning Study'). The study identified nine possible conceptions of students' understanding of the topic of 'price' in economics/business education with each being divided into a structural and a contextual element. These provide a useful framework for teacher educators to conceptualise Beginner Teachers' learning about students' understanding. In addition, Learning Study is shown to have a statistically significant, medium/large effect on the development of Beginner Teachers' knowledge of students' understandings in comparison to a control group. These results add to the evidence for adopting this approach more widely in teacher education.
\end{abstract}

\section{Keywords}

Pedagogical content knowledge, learning study, phenomenography, variation theory, teacher educators' knowledge

Department of Curriculum, Pedagogy and Assessment

UCL - Institute of Education

20 Bedford Way

London

WC1H 0AL

E-mail: g.durden@ucl.ac.uk 


\section{Introduction}

If teaching is an intentional act, to teach well, teachers must know how to organise instruction based on their knowledge of the difference between a good way of understanding any particular object of learning and a less good way. Shulman (1987) proposed that good content knowledge is not sufficient for this and that good pedagogical content knowledge (PCK) is also required. He suggested that PCK consists of two components: i) knowledge of students' specific learning difficulties and conceptions of subject phenomena and, ii) knowledge of instructional strategies. Empirical research has highlighted the importance of Shulman's components for school students' learning (Baumert, 2010), and since they are not logically restricted to any particular teaching context, suggests they could be important in other areas, such as teacher education. It follows that good teacher educators need a good knowledge of Beginner Teachers' (BTs') understanding (of students' understandings) and a good knowledge of instructional strategies to improve it (Goodwin \& Kosnik, 2013).

This study offers a new perspective on these two components of teacher educators' knowledge by examining them in terms of phenomenography/variation theory (PVT). Phenomenography is an approach to researching and describing qualitative differences between the ways in which people understand phenomena (Marton, 2015). It results in pithy descriptions of more and less sophisticated ways of understanding (referred to as conceptions) that are assumed to be structurally related (most often in a nested way). PVT proposes that organising instruction based upon highlighting important differences between conceptions is a good way of triggering students' conceptual development. This is most commonly applied to teaching situations in a collaborative approach known as ‘Learning Study' (Pang \& Marton, 2003).

This study applies PVT to the first of Shulman's knowledge components by identifying and describing qualitative differences between BTs' conceptions of students' understanding. It then addresses Shulman's second component by examining the extent to which an approach to instructional design based on BTs' conceptions (i.e. Learning Study) can contribute to the development of their understanding.

This application of PVT offers new evidence that contributes to teacher educators' PCK, to the emerging literature on teacher educators' knowledge (Selmer et al., 2016) and to the wider debate on PCK, where there have been challenges of definition and measurement (Kind, 2009). It also extends the small body of existing PVT research that has examined BTs' knowledge of students' specific learning difficulties and conceptions of subject related phenomena (Kellner et al., 2011) or made reference to PCK in general (Nilsson, 2014). Finally, in providing evidence of the extent of BTs' conceptual change following their participation in a Learning Study, this study adds to the larger body of work examining the effectiveness of PVT in teacher development (Mun \& Lo-Fu, 2013).

In order to provide background, the next section briefly examines previous research into BTs' understanding of students' understanding and its development through the perspective of PCK literature. Following this the method is described and results are presented and discussed. 


\section{Approaches to Beginner Teachers' knowledge and phenomenography/variation theory}

Teachers' understandings of students' understanding and their knowledge of instructional strategies have featured in the overwhelming majority of conceptualisations of PCK (Depaepe et al., 2013). There have broadly been two approaches to PCK. From one viewpoint, both of Shulman's knowledge components are inextricably embedded in the act of teaching and are a highly dynamic form of knowledge in action (Marks, 1990). Here the object of learning is mainly co-constructed through the interactions between teacher and students. An alternative viewpoint emphasises the role that PCK plays in preparing for teaching (Baumert et al., 2010). Here teachers draw upon a number of different types of knowledge to develop an intended object of learning in advance of teaching.

What are the implications of these approaches in teacher education? On the one hand, models of teachers' knowledge that focus on classroom interactions may capture more of the complexity of teaching, in terms of the interactions between different forms of knowledge (Petrou \& Goulding, 2011). However, this complexity means they run the risk of only developing 'elusive descriptions of what PCK entails' (Depaepe et al., 2013, p.23). This is likely to be less helpful to BTs who may lack the ability to identify the critical aspects of teaching (Kind, 2009). In addition, a focus on a broadly defined PCK 'in action' might result in: i) BTs being left alone in the classroom, where they might fall back on sterile transmission approaches to teaching (Gess-Newsome, 1999) and, ii) a neglect of the pre-existing knowledge that teachers may use in the planning of their lessons (Hashweh, 2005).

On one view, statistical tests for PCK offer a way to address these issues. For example, Krauss et al. (2008) developed test items for mathematics teachers based on three separate subscales related to Shulman's two knowledge components and 'knowledge of task'. At a macro level, these tests have contributed to the broad field of teacher education, for example, through their evidence of the association between PCK and other forms of knowledge, such as content knowledge (Baumert et al., 2010). However, they do not in themselves describe qualitative differences between BTs' understandings and their statistical complexity makes it harder to understand their basis (Hill, Ball \& Schilling, 2008). This means that whilst they may be useful for measuring PCK in some circumstances, they are more difficult for teacher educators to apply in their day to day interactions with BTs.

There are many different approaches to the development of teachers' PCK. Depaepe et al. (2013) provide an extensive set of examples including: collaborative learning, mentoring, and analysing video-case studies. These approaches are not directly developed from an explicit conceptualisation of PCK (or its components). For example, 'mentoring' may help develop BTs' knowledge of students' understanding, but it is a generic instructional strategy that is not necessarily directly derived from the content or structure of BTs' knowledge. This introduces the possibility of misalignments between what teacher educators are trying to teach and how they are trying to teach it. 
Based on this discussion, what features of an approach to the development of BTs' knowledge of students' understanding are likely to be significant in teacher education? Firstly, being able to offer some measure of changes in the quality of BTs' knowledge seems to be important. Ideally this should balance the need for simplicity in the way changes are arrived at and described, with the need to reflect the complexity of teaching and learning. Secondly, to try to capture as many benefits as possible, approaches to teacher knowledge should draw on both BTs' knowledge in action as well as their knowledge about that action (Petrou \& Goulding, 2011). Thirdly, to keep attention strictly focused on the intended object of learning (i.e. BTs' conceptions of students understanding), instructional strategies should be based as clearly as possible in conceptualisations of this object.

Phenomenography/variation theory offers a way of addressing these issues. PVT proposes that the same phenomenon may be experienced in a small number of qualitatively different ways (known as conceptions). This is possible because peoples' understanding is revealed in their awareness of aspects of a phenomenon (Marton \& Tsui, 2004). For example, a skilful guitarist will be aware of different aspects of playing the guitar to a novice. An awareness of the different tones produced by the way strings are plucked could be one such aspect. PVT assumes that it is possible to distinguish between more and less powerful conceptions of a phenomenon on the basis of their structure. The structure is defined by the number of critical aspects of a phenomenon that a person is aware of and their awareness of relationships between them. According to PVT, to become aware of a new critical aspect of a phenomenon, a person should experience the difference between a situation in which it is present and one in which it is not. Following this, to embed that aspect in a new form of understanding, all aspects should be varied in order to allow learners to develop a simultaneous awareness of them all. For the novice guitarist, with all background aspects held constant, this would mean first, plucking strings in one way and then plucking them in another and next, varying the way in which strings are plucked along with (perhaps) the position of the other hand in relation to the neck of the guitar.

The principles of PVT have most often been applied to teacher development in a 'Learning Study' (Marton \& Pang, 2003). This approach involves groups of teachers working intensively on the planning, teaching and review of a small number of lessons. During this process teachers:

1. Choose an intended focus usually based on important topics or ones that students find difficult.

2. Ascertain students' pre-understandings (usually through written pre-tests and semi-structured interviews).

3. Plan and teach the lesson(s) in which critical features of a target conception are carefully varied.

4. Assess the learning that has taken place (usually using evidence from a posttest) and then revise the lesson(s).

5. Report and disseminate results (Pang \& Marton, 2003)

Lessons developed in this way have been shown to have significant effects on the depth of school student's conceptual understanding (Ming Cheung \& Yee Wong, 2014). An 
emerging body of evidence suggests that Learning Study also improves teachers' and BTs' knowledge (Cheng, 2014).

How does the application of PVT in Learning Study help address the three issues raised above in relation to BTs' knowledge? Firstly, PVT usually identifies only a small number of qualitatively different conceptions and describes them parsimoniously (stage 2 above). This makes them very usable for teacher educators in the formulation of teaching objectives and in their day to day teaching. The ranking of conceptions also allows for the application of straightforward statistical analysis to measure changes, for example in a comparison of conceptions of BTs' conceptions pre and post intervention. Secondly, Learning Study involves BTs in combining knowledge from outside the classroom (in planning) with practical experience of teaching in the classroom (stage 3 above). Both forms of knowledge have PVT as a common theoretical underpinning which along with the reviewing process (stage 4 above) can help bring both aspects together. Thirdly, in focusing on critical aspects of a target conception (stage 3 above), a Learning Study lesson is necessarily based upon evidence of students' understanding. Since PVT offers a well-established research methodology for gathering this evidence (Åkerlind, 2005), a strong alignment between conceptualisations of students' understanding and instructional strategies to develop that understanding is more likely.

\section{Method}

\subsection{Research design}

The study was designed to answer two questions: i) what are BTs' conceptions of students' understanding and, ii) how does Learning Study affect the quality of BTs' conceptions. It followed previous phenomenographic studies in comparing an intervention group, which experienced Learning Study, and a control group, which did not (Pang \& Marton, 2003). Since BTs were not randomly assigned between the two groups, the research design was quasi-experimental. Evidence of qualitative differences in BTs' conceptions of students' conceptions was gathered in pre and post-tests.

The study followed the guidelines for ethical research of the British Educational Research Association (2011). To minimise potential harm: i) the intervention group worked on Learning Study at a time in their programme where they would normally have been completing group planning of lessons, ii) preliminary results were shared with all groups and, iii) all participants were offered the opportunity to take part in further Learning Study after this study was completed. All participants consented to being involved in a quasiexperimental study.

\subsection{Context and participants}

The sample consisted of BTs seeking teacher accreditation through Post Graduate Certificate of Education (PGCE) programmes in business and economics. BTs were chosen 
from 8 universities each of which had achieved the same 'outstanding' grading in government inspections. Learning Study was included in the PGCE at two universities University A and University B ( $n=18)$. BTs at the six other universities comprised a control group $(n=65)$. The total initial sample comprised $49 \%$ of the total number of training places allocated to Business and Economics trainees in England in 2012/13. The sample size was constrained by the number of universities with an 'outstanding' grading and by the practicalities of collecting evidence from small groups of BTs in geographically dispersed universities.

\subsection{The Learning Study intervention}

All BTs from University A and University B were randomly divided into 6 groups of 3 and each group completed a Learning Study on 'price'. This topic was chosen because of its prominence in both business/economics teaching and previous PVT research (Dahlgren \& Marton, 1978; Davies \& Lundholm, 2012).

The arrangement of the Learning Study followed Pang \& Marton (2003). Firstly, PVT and Learning Study were introduced to BTs in two briefing sessions (each two hours long). Secondly, BTs developed descriptions of conceptions of price based on written evidence from the students' they would later teach. This took about 15 hours in total (spread over three sessions). Thirdly, over the next two weeks, BTs planned lessons around variation in the critical aspects of their proposed conceptions of price. They were supported by two experienced teacher educators, one of whom was also an experienced PVT researcher.

Learning Study lessons were presented to school students studying business and economics, aged $14-19$, in two comprehensive schools (School 1 and School 2). During one week, each of the 3 groups from University A taught different lessons in School 1 and each from University B taught different lessons in School 2. The schools were chosen because they had a broadly similar student intake and government inspection grading. Each lesson was taught by one BT and observed by other members of the group. Shortly after each lesson, students completed a post test (administered by the researcher/teacher educators). Over half a day (about 5 hours), BTs analysed this evidence for any changes in the sophistication of students' understandings. In a subsequent session (about 3 hours), BTs redrafted their lessons in preparation for teaching them again.

\subsection{Collection of evidence}

Evidence of BTs' understanding of students' understanding was gathered through written pre and post-tests (lasting roughly 90 minutes) undertaken at the start and towards the end of their PGCE. BTs were given a price problem related to the price of coffee. They were asked to: i) suggest qualitatively different ways in which 14 year-old and 21 year-old students might answer this problem, ii) rank possible ways of understanding the problem in terms of sophistication and, iii) explain why they ranked the conceptions in that way. The use of contrasting age groups was intended to stimulate deeper thinking.

Two versions of the price problem were developed. One set price change in the context of a single business (a school canteen) and one set it in the context of a market (the 
international market for coffee beans). Some previous research on conceptions of price has presented the problem in the context of the decision by an individual business (Marton and Pang, 2008) whilst other research (Pang \& Marton 2003) has presented price problems in the context of local markets. This study was designed to allow for the possibility that conceptions might be framed by whether the problem was set in the context of business decision-making or market forces. In each university, the BTs were randomly divided into two groups of approximately equal size and each was given a different price problem.

The reliability of the evidence was tested in semi-structured interviews with 16 randomly selected BTs, 8 after the pre-test and 8 after the post test. Each interview was conducted by an experienced researcher and lasted 25 - 35 minutes. To probe BTs' thinking, BTs were asked a mix of open and situated questions (Åkerlind, 2005). Brief prompts were used such as 'Could you tell me a bit more about this phrase you used?'. Wherever possible, the same BTs that were interviewed at the start of the study were re-interviewed at the end.

\subsection{Analysis of evidence}

Over 8 months, two researchers worked on drafting and redrafting descriptions of conceptions. This increased reliability by ensuring that the written evidence from pre and post tests and interview transcripts was repeatedly looked at with fresh eyes (Åkerlind, 2005). The researchers initially focused on grouping aspects of BTs' thinking that appeared similar. In order to capture the full range of meaning, this involved working with extracts, as well as with whole responses. During the analysis researchers maintained a high degree of openness to possible meanings in the evidence. Researchers would often draft conceptions away from the written evidence in order maintain a degree of objective distance (Prosser, 2000). To test draft descriptions of conceptions, researchers repeatedly switched their focus between the written evidence and emerging descriptions as well as discussing each other's drafts.

After about 4 months, researchers began to focus on the relationships between conceptions as well as on their meaning (Ashworth \& Lucas, 2000). The search for structure triggered further revisions in descriptions of conceptions, which in turn triggered revisions in the structure. Towards the end of the 8 months and after at least 10 drafting cycles, the scale and frequency of revisions reduced and a stable set of conceptions emerged. This stability was tested through analysis of 25 written responses that had been set aside at the start. In nearly $90 \%$ of these, both researchers reached the same conclusions about which conceptions were being demonstrated.

Finally conceptions were ranked in order to conduct a statistical analysis. This required a new approach because of the non-linear structure of conceptions (see results section). BT responses were then categorised on the basis of the most sophisticated conception shown (Pang \& Marton 2003). This allowed a comparison between BTs in the Learning Study group and control groups. The Wilcoxon signed-rank test was used for part of this analysis. This test is the non-parametric analogue to the paired samples t-test and gives a measure of the statistical significance of an outcome being the result of a particular intervention, as well as the effect size. It does not assume normality in the data and is appropriate when sample size is relatively small (as here). The effect size was calculated 
using the formula: $r=Z \sqrt{ }$. The interpretation of effect size in this study followed Cohen's (2013) guidelines where a 'large' effect is $\geq 0.5$, a 'medium' effect is $\geq 0.3$ and a 'small' effect is $\geq 0.1$.

\section{Results}

\subsection{Beginner Teachers' conceptions of students' conceptions}

BTs' conceptions of differences between students' conceptions of price were inferred from their ranking of students' conceptions and their explanations for that ranking. Nine conceptions of price were identified (see Table 1.0 below), each made up of a general aspect (Columns A - C) and a subject related/contextual aspect (Rows $1-3$ ). These aspects were found to be qualitatively different and are arranged in order of increasing sophistication in Table 1.0.

Table 1.0 Beginner Teachers' conceptions of differences between students' conceptions

\begin{tabular}{|c|c|c|c|c|c|c|}
\hline & \multicolumn{3}{|c|}{ General aspects of BTs' conceptions } \\
\hline & & & & \multicolumn{3}{|c|}{ Increasing Sophistication } \\
\hline & & & & A & B & $\mathrm{C}$ \\
\hline & & & & $\begin{array}{l}\text { No explicit } \\
\text { basis for } \\
\text { qualitative } \\
\text { differences }\end{array}$ & $\begin{array}{l}\text { The number of } \\
\text { factors accounts } \\
\text { for qualitative } \\
\text { differences } \\
\text { (more factors } \\
\text { means more } \\
\text { complex) }\end{array}$ & $\begin{array}{l}\text { Structure } \\
\text { accounts for } \\
\text { qualitative } \\
\text { differences (the } \\
\text { more complex } \\
\text { integrates the } \\
\text { less complex) }\end{array}$ \\
\hline \multirow{3}{*}{ 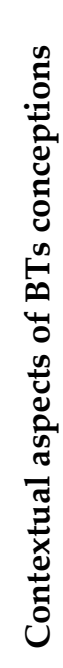 } & \multirow{3}{*}{ 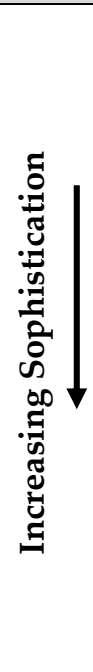 } & 1 & $\begin{array}{l}\text { Maintains one context } \\
\text { (either everyday } \\
\text { consumer experience, } \\
\text { a business context or a } \\
\text { market context) }\end{array}$ & $\begin{array}{c}\text { Conception } \\
\text { A1 }\end{array}$ & $\begin{array}{c}\text { Conception } \\
\text { B1 }\end{array}$ & $\begin{array}{c}\text { Conception } \\
\text { C1 }\end{array}$ \\
\hline & & 2 & $\begin{array}{l}\text { Identifies a change in } \\
\text { context (from } \\
\text { everyday consumer } \\
\text { experience to a } \\
\text { business context) }\end{array}$ & $\begin{array}{c}\text { Conception } \\
\text { A2 }\end{array}$ & $\begin{array}{c}\text { Conception } \\
\text { B2 }\end{array}$ & $\begin{array}{c}\text { Conception } \\
\text { C2 }\end{array}$ \\
\hline & & 3 & $\begin{array}{l}\text { Identifies a change in } \\
\text { context (from a } \\
\text { business context to a } \\
\text { market context) }\end{array}$ & $\begin{array}{c}\text { Conception } \\
\text { A3 }\end{array}$ & $\begin{array}{c}\text { Conception } \\
\text { B3 }\end{array}$ & $\begin{array}{c}\text { Conception } \\
\text { C3 }\end{array}$ \\
\hline
\end{tabular}

In terms of the general aspects, BTs' conceptions varied according to the degree of structure they contained. At the lowest level (Column A), BTs typically presented a series of conceptions based on isolated factors that they perceived students would understand 
affecting the price of coffee. By contrast, other BTs presented an increase in the sophistication of students' conceptions of price in terms of a number of factors (Column B). Finally, some BTs offered a nested set of conceptions, where the less complex was more or less explicitly integrated into the more complex (Column C). These hierarchies were similar to those proposed in previous research (Marton \& Pang, 2008).

In terms of the contextualised aspects, the lowest conception (Row 1) was expressed by BTs who set differences in students' understanding of price in a single context. This context was either everyday consumer experience of price, a business perspective on price or a market perspective on price. These contexts are similar to previously identified categories (Durden, 2018a). Rows 2 and 3 focused on shifts between these contexts. Since the type of conception represented by Row 1 was a logical pre-cursor to those in Rows 2 and 3, it was interpreted as being a less sophisticated form of understanding. Since a market perspective is more abstract and distant from everyday experience than a business context, Row 3 was considered the most sophisticated.

\subsection{Evidence of Beginner Teachers' conceptions of students' conceptions}

The extracts below illustrate the differences between the conceptions. In Extracts 1 and 2, BT's proposed that students would only see price in a single context (Row 1). In Extract 1 there is a strong sense of the importance of everyday experience when the BT states '14 year olds have been given a lunch budget for the day and will look at how much they can receive for that amount'. However it is difficult to discern a clear rationale for the order of the proposed conceptions. For example, the notion of 'disposable income' seems to be emphasised for both the 14 year old (in Conception 1) and the 21 year old (in Conception 3), along with the notion of the price of substitutes (see Conception 2 for both 14 and 21 year olds). However it is not clear why for the 14 year old disposable income is placed above the price of substitutes and yet for the 21 year old it is placed below it. This sort of inconsistency is typical of BTs' responses that fell into Column A.

\section{Extract 1(Q2) - Conception A1}

Proposed ways of student thinking - 14 year olds (in order of decreasing sophistication):

1. Amount of money left over after lunch was paid for

2. Same price as another drink, but providing different options

3. Other products in canteen maybe cheaper way of getting more for your money

Proposed ways of student thinking - 21 year olds:

1. Value for money

2. Costs against other products

3. Disposable income

\section{Rationale:}

14 year olds may have been given a lunch budget for the day and will look at how much they can receive for that amount, providing that the student can get enough food then strategic pricing may place the $75 p$ drink in that category. With the 21 year olds other aspects of budgeting may be taken into account, such as travel, car, the need for saving etc.

Extract 2 is taken to illustrate Conception B1 since they refer to multiple factors in the determination of price and do not clearly indicate a shift in context. Here, lower level 
conceptions of price are not imagined as including a consideration of costs, whereas high level conceptions are based on costs and an understanding of the impact on profit of the canteen's status as the single seller of coffee.

\author{
Extract $2(Q 2)-$ Conception B1 \\ Extract from suggested rationale: \\ Some students will assume that the school canteen is just there to make money and will \\ ignore the costs behind production. Some students will be sceptical and assume that the \\ canteen will take advantage of their position as the sole trader for coffee. Some students will \\ combine this and reason that the price is based on the canteens position and profit making.
}

Extracts 3 - 5 illustrate Row 2 of Table 1.0. In Extract 3, the rationale suggests a shift from experience to a business perspective in the use of the phrase 'not taking the price at face value'. The difference between the suggested conceptions for the 14 year old (based largely on direct experience) and the suggested conceptions for the 21 year old (based largely on business concepts) supports this interpretation. This conception was classified as Conception A2 because it is not easy to discern an explicit basis of the differences between conceptions.

Extract $3(Q 2)$ - Conception A2

Proposed ways of student thinking - 14 year olds (in order of decreasing sophistication):

1. Most students would price according to the price in their own school canteen

2. Some students would price lower as they have no like of coffee

3. Some students would price lower as they believe students can't afford $75 p$

4. Some students may price higher as they are not thinking of consequences to students or demand

5. Some students would keep price the same as they believe it would require less thought as the previous owner had it at $75 p$

Proposed ways of student thinking - 21 year olds:

1. Set price according to demand figures

2. Conduct market research

3. Set price according to the average price of coffee purchased by the student Rationale:

The answers to question 1 have been placed as they have because I believe that 14 year old students would price according to their own experience, setting and surroundings.

Whereas, 21 year old students have more life experience and assuming more academic knowledge. Therefore, research to them would be crucial as oppose(d) to taking a price at face value.

Extract 4 refers to a change from one to many factors (Column B). This is implied by the inclusion of the notion of 'profit/breakeven' as representing a more sophisticated conception. 'Breakeven' combines the ideas of sales, costs and profit, as this BT points out.

Extract 4 (Q1)-Conception B2

Rationale:

A group of 14 year olds may think that a cup of coffee is expensive for example, they may not have enough money to buy a cup of coffee...........this does not require 14 year olds to think 
too much, it is an observation on pricing. 21 year olds will think more about business terms for example, sales, costs and profit........... feel that profit/breakeven is most important as pupils start thinking why sell cups of coffee.

There was only one BT who exhibited Conception C2. This BT presented a set of conceptions that were quite tightly nested within each other (particularly in relation to the 21 year olds). However, these were only set in a market context. The use of the terms 'buyers' and 'sellers' and 'producers' and 'consumers' is strongly indicative of this. The BT explains the difference between conceptions in terms of 'awareness of the coffee market' or of some conceptions being 'more basic' than others. However, it was not possible from the data provided to be sure what these phrases mean. It is not clear whether this BT had a rationale for differences or whether it was not revealed in this evidence. As a result, Extract 5 was classified as Conception C2.

Extract $5(Q 1)-$ Conception C2

Proposed ways of student thinking - 14 year olds (in order of decreasing sophistication):

1. Compromise between producer and consumer

2. Power of buyers over sellers

3. Amount of coffee drunk in the world

4. Price charged by producers

Proposed ways of student thinking - 21 year olds:

1. Compromise between producers and consumers, taking into account external factors

2. Power of buyers as they don't want to pay too much

3. Incentive by producers to encourage buyers to buy their product.

Rationale:

For 21 year olds there is more awareness of the coffee market and difficulties in trade between developed and developing parts of the world. This is taken into account at all 3 levels. 2 and 3 are fairly similar but look at the issue from different perspectives. 14 year olds have less awareness of the coffee market with this only being apparent at the top of the pyramid. The lower levels are much more basic than lower levels for the 21 year olds.

Extract 6 refers to Row 3 in Table 1.0. It is one of a very small number of examples of Conception A3 where a shift from a business context to a market context for price is evident. This is seen in the difference between the conceptions for a 14 year old, which are mainly business oriented (particularly Conceptions 3 and 4), and those of the 21 year old, which are market oriented (referring to general features of markets - such as scarcity and market power). The rationale - whilst in note form - also provides support for this in focusing on costs and production techniques (business oriented ideas) as being 'easy to imagine' with subsidies and regulation (more market oriented ideas) being more complex because they are not 'so direct'.

Extract 6 (Q1) - Conception A3

Proposed ways of student thinking - 14 year olds (in order of decreasing sophistication):

1. Transport and farmers costs

2. Weather and product techniques

3. Profit of coffee companies

4. How it is marketed, TV adverts, radio 
Proposed ways of student thinking - 21 year olds:

1. Trade agreements, tariffs, subsidies

2. Demand for product

3. Scarcity of product

4. Existence of powerful multi-national companies

Rationale:

Transport and farmers costs are easy to imagine awareness of coffee beans grown abroadtransport costs. Idea that production technique affect the amount of production. 21 year olds very aware of multi-national companies and understand they 'rip off' farmers. Hardest concept is how UK subsidies and regulations may affect farmers in the tropics because they are not direct.

In comparison to Extract 6 above, Extract 7 offers a combination of factors as representing higher levels of sophistication. It does this in its reference to 'supply and demand' for 21 year olds and 'price elasticity' for 14 year olds (price elasticity represents a combination of a change in price in relation to a change in demand). The rationale implies that lower level conceptions are based on students' experience (at Starbucks) and that high level conceptions 'relate back to theory'. Given the use of the terms 'subsidy', 'price elasticity' and 'supply and demand' this 'theory' is interpreted as being illustrative of a market perspective.

Extract 7 (Q2) - Conception B3

Proposed ways of student thinking - 14 year olds (in order of decreasing sophistication):

1. Price elasticity

2. Subsidies

3. Costs

4. Market research

5. Competitors prices

Proposed ways of student thinking - 21 year olds:

1. Supply and demand

2. Price elasticity (higher level)

3. Subsidies

Rationale:

I feel that students would come up with answers that are more practical to them at the beginning. From their experience as consumers you should be able to relate it back to theory....... a student is quite likely to notice that a Starbucks coffee is far more than $75 p$. From here it will probably be easy to move them on to different costings and subsidies.

The final extract illustrates the highest conception (C3 in Table 1.0). In Extract 8 there is a shift from students' direct experience of business (represented as something that they would 'talk more easily about') to a market perspective where demand and supply is highlighted. Conceptions 3, 4 and 5 identified by the BT for 14 year olds seem nested together in the sense that costs precede a calculation of profits which (if a cost plus model is assumed) could be said to lead to market price. Then moving to a market perspective in Conceptions 1 and 2, 'supply' is followed by 'demand' and then 'supply and demand' (Conception 3 for the 21 year old). Finally Conceptions 2 and 1 for the 21 year old could 
both be seen as macro-economic factors bearing on the operation of supply and demand (although it is not clear why they are in the order that they are).



\subsection{Learning Study and Beginner Teachers' knowledge}

In order to analyse the effects of Learning Study, each BT was categorised according to the conceptions in Table 1.0, and then each conception was assigned a ranking (Table 2.0). Rankings were derived from the frequency of each conception. For example, a BT with Conception C1 would logically also have addressed Conception B1 and Conception A1 and so on. It was assumed that a conception with a higher frequency would attract a lower ranking.

Table 2.0 - Rankings of BTs' conceptions (1 is the lowest ranking)

\begin{tabular}{|l|c|c|c|c|c|c|c|c|c|}
\hline Conception in Table 1.0 & A1 & A2 & A3 & B1 & B2 & B3 & C1 & C2 & C3 \\
\hline Ranking of conceptions & 1 & 3 & 5 & 2 & 4 & 5 & 6 & 6 & 6 \\
\hline
\end{tabular}

The above rankings were used to calculate median and mean rankings in both Learning Study and control groups (Table 3.0). 
Table 3.0-Median and mean rankings in pre and post-tests

\begin{tabular}{|l|l|c|c|}
\hline \multicolumn{2}{|c|}{} & $\begin{array}{c}\text { Control group } \\
(\mathbf{n = 6 5 )}\end{array}$ & $\begin{array}{c}\text { Learning Study group } \\
(\mathbf{n = 1 8 )}\end{array}$ \\
\hline \multirow{2}{*}{ Median ranked conception } & Pre & 2.00 & 2.00 \\
\cline { 2 - 4 } & Post & 2.00 & 3.50 \\
\hline \multirow{2}{*}{ Mean ranked conception } & Pre & 2.89 & 2.55 \\
\cline { 2 - 4 } & Post & 2.60 & 3.61 \\
\hline
\end{tabular}

These data suggest that Learning Study has a beneficial effect on BTs' knowledge. Whilst the mean rankings for the control group were broadly similar in both pre and post tests, those for the Learning Study group rose (by 1.5 for median rankings and 1.06 for mean rankings). Overall, $56 \%$ of BTs increased the sophistication of their conceptions in the Learning Study group, compared to 32\% in the control group. The results of the Wilcoxon signed-rank test added weight to the positive picture of Learning Study (Table 4.0).

Table 4.0 - Wilcoxon signed-rank test results and effect size

\begin{tabular}{|l|c|c|}
\hline & Control group (n=65) & Learning Study Group (n=18) \\
\hline $\mathbf{Z}$ score & 1.15 & 2.71 \\
\hline $\boldsymbol{p}$ value & 0.25 & 0.01 \\
\hline Effect size (r) & & 0.45 \\
\hline
\end{tabular}

For BTs in the control group, this test did not highlight a statistically significant effect of their PGCE programme on the development of their conceptions of students' conceptions $(p>0.05)$. However, for BTs in the Learning Study group, a medium/large, statistically significant effect $(\mathrm{p}<0.05)$ was discovered for both $(\mathrm{r}=0.45)$.

\section{Discussion}

Teachers' knowledge of their students' specific learning difficulties and conceptions of subject phenomena have been prominent in most conceptualisations of PCK (Depaepe et al., 2013). This study applies PVT to this form of knowledge and maps out qualitative differences in a topic that is central to economics and business education. These findings form a framework for teacher educators' thinking about BTs' learning about the teaching of price, by helping them to distinguish between a BT with a sophisticated conception of students' understanding and a BT with a less sophisticated conception. Two features of this framework make it easier for teacher educators to apply in the day to day practical organisation of teacher education. Firstly, the descriptions of conceptions capture the critical differences between them in a pithy way and secondly, the conceptions are logically nested within each other. These benefits might also apply to BTs who engage with the framework. Being able to easily access and understand differences between BTs' understandings of students' understandings is important. For example, a BT with Conception A1 is unlikely to be able to organise instruction to develop students' thinking 
since they do not have an understanding of the different ways in which a student might understand price or of different context.

This study found that BTs' conceptions of students' understanding consists of two components, one general (Columns A - C) and one contextual (Rows $1-3$ ). These components varied independently of each other. In other words, it is possible for BTs to have a sophisticated conception of students' general understanding of price in combination with a less sophisticated understanding of the context of price, and vice versa. This suggests that the development of BTs' knowledge relies on increasing the sophistication of their understanding along both general and contextual dimensions. This finding adds to previous research on conceptions of price, most of which do not explicitly include the context in their descriptions of conceptions (and imply that a sophisticated understanding of price is possible regardless of context (Marton \& Pang, 2008). It also supports the findings suggesting that the sophistication of BTs' understanding will be capped by their understanding of the context (Taylor \& Booth, 2015). In other words, according to the results here, the best BTs could achieve would be Conception C1 without an awareness of a change in context. This conclusion is particularly important in teacher education since a BT whose understanding is restricted to Conception C1 will not know the possible stages in the development of a students' understanding, and will therefore be less able to design instructional activities that will help them get to the higher levels.

In this study, ranking conceptions made it possible to develop quantitative measures of conceptual change. Assuming that BTs' conceptions are stable enough to allow a single conception to be meaningfully ascribed to a particular individual, findings suggest that BTs in the control group did not experience a statistically significant increase in the quality of their understanding during their teacher education programmes. If the results of this study are reliable, this represents a sobering outcome for the teacher educators at these six universities, particularly given the centrality of the topic of 'price' in the subject domain and the strong likelihood that BTs would have had to teach it. By contrast, in the Learning Study group, BTs experienced a statistically significant medium/large effect on their conceptual understanding.

What could account for the difference between the control and intervention groups? One possibility, consistent with PVT, is that the Learning Study process exposed BTs to variation between their prior understandings and other understandings in a relatively structured way. Learning Study involves groups of teachers in plan, teach and review cycles where lessons are based on a phenomenographic analysis of students' conceptions and teaching activities designed around variation theory. This means that BTs will experience variation between: i) levels of subject knowledge exhibited by different teachers, ii) different preferred approaches to teaching price and, iii) their own and others understanding of students' understanding (Wong \& Lo, 2008). According to variation theory, this experience of differences in critical aspects of ways of looking at a phenomenon is likely to trigger a conceptual shift (Marton \& Tsui, 2004). Whilst it is possible that BTs in the control group may have experienced some of the variation noted above, this variation may not have taken place in the same structured way as in a Learning Study and therefore was not 'activated' to the same extent. 
Although results in this study suggest that Learning Study had a more powerful effect than other forms of teacher education, this effect may have been limited by a number of factors. Firstly, the BTs in this study may have only had relatively low levels of content knowledge. Although BTs had good degree classifications in business and economics, the distinctive nature of school based knowledge could still mean that their content knowledge was at a relatively low level. Without a sophisticated understanding themselves, it is difficult to see how BTs could develop a sophisticated understanding of students' understanding (Deng, 2007). This has been confirmed in a number of studies of PCK (Baumert et al., 2010). Secondly, BTs in the intervention group may have found it challenging to manage the variation that they were exposed to. Variation theory proposes that learning occurs through the careful construction of teaching activities that (initially at least) highlight variation in a single aspect of difference between conceptions. Since the focus of most Learning Studies is student learning, it is therefore not a requirement of the approach that teachers are exposed to variation in the same meticulous way that students are. This opens up the possibility of teachers being overwhelmed by the experience of 'too much' variation, something that might particularly apply to novice BTs (Durden, 2018b).

There are a number of limitations in this study. Firstly, pre and post tests proved demanding for many BTs, perhaps because they involved a type of thinking not previously encountered. This restricted the detail in some BTs' responses and made interpretation challenging. There was a good alignment between the conceptions revealed in the interviews and those in the written responses, but this may not have applied to every BT. Secondly, the grid layout of the findings in Table 1.0 necessitated a new approach to ranking conceptions. Whilst the statistical approach taken did marry well with a priori reasoning, this way of establishing final rankings has not previously been used in other PVT studies.

\section{Conclusion}

This study contributes to teacher educators' PCK by applying phenomenography/variation theory to BTs' understandings of students' understandings. It provides new evidence of the way in which this can be researched and described and suggests that Learning Study is a good prospect for developing BTs' knowledge. This is likely to be a result of its systematic focus on students' understanding, the clear link to instructional design and the collaborative aspects.

\section{References}

Åkerlind, G. S. (2005) ‘Variation and commonality in phenomenographic research methods', Higher Education Research \& Development, 31(1), pp. 115-127. doi: 10.1080/07294360.2011.642845.

Ashworth, P. and Lucas, U. (2000) 'Achieving empathy and engagement: a practical approach to the design, conduct and reporting of phenomenographic research', Studies in Higher Education, 25(3), pp. 295-308. doi: 10.1080/713696153. 
Baumert, J. et al. (2010) 'Teachers' mathematical knowledge, cognitive activation in the classroom, and student progress', American Educational Research Journal, 47(1), pp. 133-180. doi: $10.3102 / 0002831209345157$.

British Educational Research Association (2011) Ethical Guidelines for Educational, British Educational Research Association. London: BERA. doi: 978-0-946671-32-8.

Cheng, E. C. K. (2014) 'Learning Study: nurturing the instructional design and teaching competency of pre-service teachers', Asia-Pacific Journal of Teacher Education, 42(1), pp. 5166. doi: 10.1080/1359866X.2013.869546.

Cohen, J. (2013) Statistical Power Analysis for the Behavioral Sciences. Routledge. doi: $10.4324 / 9780203771587$.

Davies, P. and Dunnill, R. (2008) "'Learning Study" as a model of collaborative practice in initial teacher education', Journal of Education for Teaching, 34(1), pp. 3-16. doi:

10.1080/02607470701773408.

Davies, P. and Lundholm, C. (2012) 'Students' understanding of socio-economic phenomena: Conceptions about the free provision of goods and services', Journal of Economic Psychology, 33(1), pp. 79-89. doi: 10.1016/j.joep.2011.08.003.

Deng, Z. (2007) 'Knowing the subject matter of a secondary-school science subject', Journal of Curriculum Studies, 39(5), pp. 503-535. doi: 10.1080/00220270701305362.

Depaepe, F., Verschaffel, L. and Kelchtermans, G. (2013) ‘Pedagogical content knowledge: A systematic review of the way in which the concept has pervaded mathematics educational research', Teaching and Teacher Education. Elsevier Ltd, 34, pp. 12-25. doi: 10.1016/j.tate.2013.03.001.

Durden, G. (2018a) 'Accounting for the context in phenomenography-variation theory: evidence of English graduates' conceptions of price', International Journal of Educational Research, 87, pp. 12-21. doi: 10.1016/j.ijer.2017.11.005.

Durden, G. (2018b) 'Improving teacher learning: variation in conceptions of learning study', International Journal for Lesson and Learning Studies, 7(1). doi: 10.1108/IJLLS-09-20170041.

Gess-Newsome, J. (1999) 'Pedagogical content knowledge: an introduction and orientation', in Gess-Newsome, J. and Lederman, G. S. (eds) Explaining Pedagogical Content Knowledge. Dordrecht, The Netherlands: Kluwer Academic. doi: 10.1007/0-306-47217-1_2.

Goodwin, A. L. and Kosnik, C. (2013) 'Quality teacher educators = quality teachers? Conceptualizing essential domains of knowledge for those who teach teachers', Teacher Development, 17(3), pp. 334-346. doi: 10.1080/13664530.2013.813766.

Hashweh, M. Z. (2005) 'Teacher pedagogical constructions: a reconfiguration of pedagogical content knowledge', Teachers and Teaching, 11(3), pp. 273-292. doi: 10.1080/13450600500105502.

Hill, H. C., Ball, D. L. and Schilling, S. G. (2008) `Unpacking pedagogical content 
knowledge : Conceptualizing and measuring teachers ' topic-specific knowledge of students', Journal for Research in Mathematics Education, 39(4), pp. 372-400. doi: Article.

Kellner, E. et al. (2011) 'Prospective teachers' initial conceptions about pupils' difficulties in science and mathematics: a potential resoure in teacher education', International Journal of Science and Mathematics Education, 9(4), pp. 843-866. doi: 10.1007/s10763-010-9232-5.

Kind, V. (2009) 'Pedagogical content knowledge in science education: Perspectives and potential for progress', Studies in Science Education, 45(2), pp. 169-204. doi: 10.1080/03057260903142285.

Krauss, S. et al. (2008) 'Pedagogical content knowledge and content knowledge of secondary mathematics teachers.', Journal of Educational Psychology, 100(3), pp. 716-725. doi: 10.1037/0022-0663.100.3.716.

Marton, F. (2015) Necessary conditions of learning. London: Routledge.

Marton, F. and Pang, M. F. (2008) 'The idea of phenomenography and the pedagogy of conceptual change', in International handbook of research on conceptual change. London: Routledge, pp. 563-576.

Ming Cheung, W. and Yee Wong, W. (2014) 'Does Lesson Study work?', International Journal for Lesson and Learning Studies, 3(2), pp. 137-149. doi: 10.1108/IJLLS-05-2013-0024.

Nilsson, P. (2014) 'When teaching makes a difference: Developing science teachers' pedagogical content knowledge through learning study', International Journal of Science Education, 36(11), pp. 1794-1814. doi: 10.1080/09500693.2013.879621.

Pang, M. F. and Marton, F. (2003) 'Beyond "lesson study": Comparing two ways of facilitating the grasp of some economic concepts', Instructional Science. Springer, 31, pp. 175-194. doi: 10.2307/41953614.

Petrou, M. and Goulding, M. (2011) 'Conceptualising teachers' mathematical knowledge in teaching', in Rowland, T. and Ruthven, K. (eds) Mathematical knowledge in teaching. Dordrecht: Springer, pp. 9-27.

Prosser, M. (2000) 'Using phenomenographic research methodology in the context of research in teaching and learning', in Bowden, J. and Walsh, E. (eds) Phenomenography. Melbourne: RMIT University Press, pp. 24-32.

Selmer, S., Bernstein, M. and Bolyard, J. (2016) ‘Multilayered knowledge: understanding the structure and enactment of teacher educators' specialized knowledge base', Teacher Development, 20(4), pp. 437-457. doi: 10.1080/13664530.2016.1173578.

Shulman, L. (1987) 'Knowledge and teaching: Foundations of the new reform', Harvard Educational Review, 57(1), pp. 1-23. doi: 10.17763/haer.57.1.j463w79r56455411.

Taylor, D. L. and Booth, S. (2015) 'Secondary physical science teachers' conceptions of science teaching in a context of change', International Journal of Science Education, 37(8), pp. 1299-1320. doi: 10.1080/09500693.2015.1035356. 
Wong, C. Y. and Lo, M. L. (2008) 'The implementation of the project', in Lo, M. L. et al. (eds) Variation for the improvement of teaching and tearning final report: Centre for Learning Study and School Partnership. Hong Kong: Hong Kong Institute of Education, pp. 18-28.

Yee Lai, M. and Wah Priscilla Lo-Fu, Y. (2013) 'Incorporating learning study in a teacher education program in Hong Kong: a case study', International Journal for Lesson and Learning Studies, 2(1), pp. 72-89. doi: 10.1108/20468251311290141. 